\title{
A multisite, randomized field trial to evaluate the influence of lactoferrin on the morbidity and mortality of dairy calves with diarrhea
}

\author{
J. A. Pempek, L. R. Watkins, C. E. Bruner, and G. G. Habing* \\ Department of Veterinary Preventive Medicine, The Ohio State University, Columbus 43210
}

\section{ABSTRACT}

Diarrhea is one of the most common causes of antimicrobial use and mortality in young calves. To reduce antimicrobial use and resistance on dairy farms, research on alternative therapies for calf diarrhea is necessary. Our laboratory previously conducted a randomized clinical trial investigating the effectiveness of lactoferrin, an iron-binding protein found in colostrum, as a treatment for calf diarrhea. The trial showed significantly reduced calf mortality in diarrheic calves that were administered lactoferrin. Thus, the objective of this study was to corroborate the results of our prior clinical trial across multiple farms and to investigate the effect of lactoferrin on the morbidity and mortality of preweaned calves with naturally occurring cases of diarrhea. This randomized field trial was conducted on 5 commercial dairy farms in Ohio. In total, 485 calves ( $\leq 21 \mathrm{~d}$ of age) were enrolled at first diarrhea diagnosis (fecal score $\geq 2$ defined as loose to watery) and randomly assigned to receive an oral dose of lactoferrin (3 $\mathrm{g}$ of lactoferrin powder dissolved in $30 \mathrm{~mL}$ of water) or $30 \mathrm{~mL}$ of water (control) once daily for 3 consecutive days. Health assessments were conducted on the day of diarrhea diagnosis (d 0) and 1, 2, 3, 7, 14, 21, 28 , and $35 \mathrm{~d}$ following diagnosis. Producer records of disease treatment and mortality were collected $120 \mathrm{~d}$ following diagnosis. A Poisson regression model was used to test differences between treatments in disease frequency through $35 \mathrm{~d}$ post-diarrhea diagnosis and the incidence risk of treatment and mortality risk $120 \mathrm{~d}$ post-diarrhea diagnosis; the model controlled for calf age at enrollment, farm, and treatment. Median calf age at enrollment was $11 \mathrm{~d}$ and ranged from 1 to $26 \mathrm{~d}$ of age. At study enrollment, 51.3\% (123/240) and 52.2\% $(128 / 245)$ of calves in the control and lactoferrin treatment groups, respectively, were diagnosed with severe diarrhea (fecal score $=3$ ). The frequency of disease

Received February 12, 2019.

Accepted May 20, 2019.

*Corresponding author: habing.4@osu.edu (diarrhea, dehydration, depression, signs of respiratory disease) through $35 \mathrm{~d}$ following diarrhea diagnosis was not significantly different for calves in the lactoferrin and control groups. Overall mortality risk for enrolled calves was $9.9 \%$, and $10.7 \%(22 / 243)$ and $9.1 \%$ (26/242) of calves in the lactoferrin and control groups, respectively, died or were culled in the $120 \mathrm{~d}$ following diarrhea diagnosis. The relative risk of death or culling did not differ between treatment groups, however. Therefore, as performed in this study, lactoferrin as a treatment for calf diarrhea was not beneficial.

Key words: calf diarrhea, lactoferrin, antimicrobial alternative

\section{INTRODUCTION}

Diarrhea remains one of the most common causes of antimicrobial use and mortality in preweaned dairy heifer calves in the United States (USDA, 2018). According to the National Animal Health Monitoring Survey in 2014, 21\% of preweaned dairy calves were reported to have diarrhea or other digestive problems, and more than $75 \%$ of affected calves received antimicrobial treatment (USDA, 2018). Antimicrobials used for treatment in dairy calves have an important public health impact, and those categorized as "highest priority critically important" by the World Health Organization (WHO, 2017), including third-generation cephalosporins, are commonly used to treat calf diarrhea in the United States (Constable, 2004; Pereira et al., 2014; USDA, 2018). Thus, reduced overall antimicrobial use on dairy farms necessitates research on viable alternative therapies for calf diarrhea.

Lactoferrin, an iron-binding glycoprotein naturally found in colostrum, is involved in iron homeostasis and has antimicrobial (Embleton et al., 2013), immunomodulatory (Puddu et al., 2009), and anti-inflammatory properties (Conneely, 2001). Lactoferrin has been extensively researched in humans, primarily in infants and young children (Manzoni et al., 2012; Ochoa et al., 2013; Pammi and Abrams, 2015; Manzoni, 2016), and there is evidence that lactoferrin reduces the severity and longitudinal prevalence of diarrhea (Ochoa et al., 
2013). Fewer studies have been conducted in livestock species; however, daily lactoferrin supplementation has been shown to increase ADG (Joslin et al., 2002; Robblee et al., 2003) and reduce morbidity (Robblee et al., 2003) in preweaned dairy calves.

In an earlier trial conducted on a single dairy calf ranch, our laboratory found that lactoferrin significantly reduced calf mortality or culling through $120 \mathrm{~d}$ post-diarrhea diagnosis (Habing et al., 2017). This was determined by assessing the effectiveness of lactoferrin and garlic extract compared with water (control) as a treatment for naturally occurring cases of calf diarrhea for 199, 205, and 224 calves enrolled into the lactoferrin, garlic extract, and water (control) groups, respectively. However, because our former trial was conducted on a single dairy operation, additional research across multiple dairy herds is needed to corroborate the observed reduction in mortality and culling in calves that received lactoferrin. Thus, the objective of this study was to use a multisite, randomized clinical trial to determine the effectiveness of lactoferrin as a treatment for naturally occurring cases of diarrhea in preweaned dairy calves. We hypothesized that lactoferrin would reduce the rate of disease, including diarrhea, signs of respiratory disease, depression, and dehydration, and 120 -d risk of mortality and culling when administered to calves with diarrhea.

\section{MATERIALS AND METHODS}

This multisite, randomized field trial was conducted on 5 commercial dairy farms in Ohio in accordance with the guidelines set by The Ohio State University Institutional Animal Care and Use Committee (animal use protocol 2013A00000054).

\section{Study Sites}

This trial began in March 2017 and ended in December 2017. A convenience sample of dairy farms within a 100 -mile $(161 \mathrm{~km})$ radius from The Ohio State University (Columbus) that reported raising their own replacements was selected. All calves were routinely separated from the dam and fed colostrum as soon as possible after birth via bottle or esophageal feeder. Three farms housed preweaned heifer calves outside in individual calf hutches, 1 farm housed heifer calves indoors in individual pens with solid sides, and 1 farm housed heifer calves indoors in individual pens separated with wire paneling. The number of farms selected was determined by the total number of calves required ( $\mathrm{n}=220$ cases $/$ group) to provide sufficient power $(\beta=0.80)$ to detect a significant $(\alpha=0.05)$ difference between treatment groups, assuming mortality rates of 13 and $5 \%$ in the control and treatment groups, respectively (Habing et al., 2017).

\section{Enrollment}

Research personnel were trained by the lead investigator before the start of the experiment to ensure proper animal handling, experimental techniques, and accuracy of disease diagnoses. All calves $\leq 21 \mathrm{~d}$ of age were visually assessed by The Ohio State University research personnel. Calves were enrolled in the trial after being diagnosed by research personnel with diarrhea (fecal score of 2 or 3; Table 1 ). New cases were enrolled $3 \mathrm{~d} / \mathrm{wk}$, and preference was given, if necessary, to more severe cases of diarrhea based on results of our previous trial, which documented a lower relative risk of death or culling in calves with watery diarrhea (fecal score of 3) compared with moderate cases of diarrhea (fecal score of 2; Habing et al., 2017). Calves were excluded from possible enrollment if they were severely depressed (score of 3) or if they were diagnosed with diarrhea and subsequently treated by farm personnel on nonenrollment days or days when research staff did not visit the farm. Following diarrhea diagnosis, a clinical health examination was conducted, and a fecal and blood sample was obtained from each calf before experimental treatment administration. All necessary nonexperimental therapies for diarrhea (e.g., fluids, antimicrobials) were administered by farm personnel according to individual farm protocols (Table 2), but experimental study treatments (lactoferrin and control) were administered only by research personnel.

\section{Experimental Treatments}

Lactoferrin was commercially prepared and obtained as a freeze-dried protein from bovine milk (The Tatua Co-operative Dairy Company Ltd., Morrinsville, New Zealand). Lactoferrin treatments were prepared onfarm by dissolving $3 \mathrm{~g}$ of lactoferrin powder in $30 \mathrm{~mL}$ of distilled water; treatments were prepared in advance and stored at $4^{\circ} \mathrm{C}$ for $24 \mathrm{~h}$ to increase product solubility. Calves meeting the criteria for study enrollment received once-daily treatments of either $30 \mathrm{~mL}$ of distilled water (control) or $30 \mathrm{~mL}$ of distilled water containing $3 \mathrm{~g}$ of lactoferrin for 3 consecutive days. All treatments were administered via oral dosing syringe.

Calves were randomized (Microsoft Excel, Microsoft Corp., Redmond, WA) to either the control or the lactoferrin treatment groups by the research coordinator in blocks of 2, with a randomly assigned within-block order of treatments. In other words, once calves were 
Table 1. Description of the scoring systems used for signs of respiratory disease, diarrhea, depression, and dehydration in the present study

\begin{tabular}{|c|c|c|c|c|}
\hline Health concern & \multicolumn{4}{|c|}{ Score } \\
\hline Nasal discharge & $\begin{array}{l}\text { Normal serous } \\
\text { discharge }\end{array}$ & $\begin{array}{l}\text { Small amount of unilateral } \\
\text { cloudy discharge }\end{array}$ & $\begin{array}{l}\text { Bilateral cloudy or excessive } \\
\text { mucus discharge }\end{array}$ & $\begin{array}{l}\text { Copious bilateral } \\
\text { mucopurulent discharge }\end{array}$ \\
\hline Ocular discharge & Normal & $\begin{array}{l}\text { Small amount of ocular } \\
\text { discharge }\end{array}$ & $\begin{array}{l}\text { Bilateral cloudy or excessive } \\
\text { mucus discharge }\end{array}$ & $\begin{array}{l}\text { Copious bilateral } \\
\text { mucopurulent discharge }\end{array}$ \\
\hline Cough & None & Induced single cough & $\begin{array}{l}\text { Induced repeated coughs } \\
\text { or occasional spontaneous } \\
\text { cough }\end{array}$ & $\begin{array}{l}\text { Repeated spontaneous } \\
\text { coughs }\end{array}$ \\
\hline Diarrhea & Normal & Semiformed; pasty & $\begin{array}{l}\text { Loose; stays on top of } \\
\text { bedding }\end{array}$ & $\begin{array}{l}\text { Watery; sifts through } \\
\text { bedding }\end{array}$ \\
\hline Depression & $\begin{array}{l}\text { Normal; no signs of } \\
\text { depression }\end{array}$ & $\begin{array}{l}\text { Mild depression; calf suckles } \\
\text { but not vigorously }\end{array}$ & $\begin{array}{l}\text { Moderate depression; calf } \\
\text { able to stand; suckling is } \\
\text { weak or disorganized }\end{array}$ & $\begin{array}{l}\text { Severe depression; calf } \\
\text { unable to stand or suckle }\end{array}$ \\
\hline Dehydration & $\begin{array}{l}\text { Normal; eyes are } \\
\text { bright and skin feels } \\
\text { pliable }\end{array}$ & $\begin{array}{l}\text { Mild dehydration; slight loss } \\
\text { of skin elasticity; skin tent } \leq 3 \\
\text { s; eyes not recessed into orbit }\end{array}$ & $\begin{array}{l}\text { Moderate dehydration; skin } \\
\text { tent }>3 \mathrm{~s} \text { but }<10 \mathrm{~s} \text {; eyes } \\
\text { slightly recessed into orbit }\end{array}$ & $\begin{array}{l}\text { Severe dehydration; skin } \\
\text { tent }>10 \text { s; eyes markedly } \\
\text { recessed into orbit }\end{array}$ \\
\hline
\end{tabular}

diagnosed with diarrhea, lactoferrin and water (control) treatments were randomly assigned to calves in groups of 2 (e.g., block 1: calf $1=$ lactoferrin, calf $2=$ control; block 2: calf $3=$ control, calf $4=$ lactoferrin). This approach was used to distribute treatments evenly between and within farm locations over the course of the trial and to prevent anticipation of treatment allocation by research personnel. All farm personnel were blinded to treatment assignments. Although perfect blinding for research personnel was not possible because the same research personnel were responsible for conducting health assessments and mixing and administering treatments, health examinations were completed for all calves before treatment administration, and study personnel were generally unaware of treatment assignments when recording subjective health assessment data due to the large number of enrolled cases.

\section{Farm Therapies for Calf Diarrhea}

Each farm had a different diarrhea case definition to initiate therapy (Table 2). Routine therapies for calf diarrhea for each farm were administered at the discretion of farm personnel independent of research staff diarrhea diagnosis and study enrollment. Calves diagnosed with diarrhea by the research staff could go undiagnosed by farm personnel depending on the farm and their case definition of diarrhea. Two farms used fecal consistency as the only sign to initiate therapy, similar to our enrollment criteria, and the remaining 3 farms considered fecal consistency and signs of systemic illness (e.g., inappetence or attitude) to initiate therapy. Each farm also followed a different diarrhea treatment regimen, which varied from the use of antidiarrheal medicine to different antimicrobials, with and without fluid therapy.

\section{Data Collection}

Health. Fecal samples were collected from each calf at study enrollment to confirm diarrhea cases. Health examinations were conducted on the day of diarrhea diagnosis (e.g., study enrollment) and 1, 2, 3, 7, 14, 21, 28, and $35 \mathrm{~d}$ postenrollment. The physical health examination (Table 1) included rectal temperature at diarrhea diagnosis and scores for fecal consistency (4-point scale; McGuirk, 2008), signs of respiratory disease (4-point scale; McGuirk, 2008), depression (4-point scale; Constable et al., 1998), and dehydration (skin tent test, 4-point scale; Constable et al., 1998). Health outcome

Table 2. Diarrhea case definitions and farm therapies for the 5 farms enrolled in this trial

\begin{tabular}{lcll}
\hline $\begin{array}{l}\text { Farm } \\
\text { no. }\end{array}$ & $\begin{array}{c}\text { No. of } \\
\text { cases }\end{array}$ & Diarrhea diagnosis & Routine farm treatments \\
\hline 1 & 72 & Fecal consistency and depression & Spectinomycin \\
2 & 124 & Fecal consistency and depression & Ceftiofur, electrolytes \\
3 & 47 & Fecal consistency only & Sulfadimethoxine \\
4 & 111 & Fecal consistency and inappetance & Sulfamethoxazole \\
5 & 131 & Fecal consistency only & Kaolin, pectin $\left(\right.$ Kao-Pec $\left.{ }^{1}\right)$ \\
\hline
\end{tabular}

${ }^{1}$ Agri Laboratories Ltd. (St. Joseph, MO). 
scores were dichotomized using biologically relevant cut-offs. Health outcomes were considered clinically normal if fecal score $=0$ or 1 , depression score $=0$ or 1 , navel inflammation score $=0$ or 1 , and skin tent score $=0$ or 1 . Diarrhea was defined as a fecal score $=2$ or 3 , and severe diarrhea was defined as a fecal score $=3$. Depression was defined as a depression score $=2$ or 3 , navel inflammation was defined as a navel score $=2$ or 3 , and a fever was defined as a temperature $\geq 39.4^{\circ} \mathrm{C}$. Complicated diarrhea was considered separately as diarrhea with depression. Ocular discharge or head tilt or ear position, nasal discharge, and induced or spontaneous cough were considered signs of respiratory disease, and scores $=2$ or 3 were considered abnormal. Calves were considered dehydrated if the skin remained tented $>3 \mathrm{~s}$ ( score $=2$ or 3 ). Records of disease events and treatments as well as mortality were maintained by farm personnel and collected through $120 \mathrm{~d}$ following enrollment in the trial.

Blood Samples. On the day of enrollment, blood samples from the jugular vein were collected into 10$\mathrm{mL}$ vacuum tubes (Monoject Blood Collection Tubes, Covidien, Mansfield, MA), with and without EDTA liquid additive, using a 20-gauge, 1-inch $(2.54 \mathrm{~cm})$ blood collection needle (Monoject, Covidien). Blood samples were immediately placed on ice, where they remained until being transported to the laboratory for further processing. Blood analyses were conducted at The Ohio State University College of Veterinary Medicine (Columbus) or the Ohio Agriculture Research and Development Center, Food Animal Health Research Center (Wooster), depending on farm location.

Packed Cell Volume and Total Protein. Whole blood from EDTA-coated tubes was drawn into capillary tubes (40-mm glass capillary tube, Beckman Coulter Inc., Indianapolis, IN) and centrifuged at 10,000 $\times g$ for 3 min at $4^{\circ} \mathrm{C}$. Capillary tubes were read using a micro-hematocrit capillary tube reader (McCormick Scientific LLC, St. Louis, MO) to evaluate dehydration ( $>46 \%$ packed red blood cell count; Kahn et al., 2010) via measure of packed cell volume. In addition, blood samples from plain serum tubes were centrifuged at $1,180 \times g$ at $4^{\circ} \mathrm{C}$ for $15 \mathrm{~min}$. Total serum protein was analyzed using a hand-held refractometer, and blood serum was stored at $-20^{\circ} \mathrm{C}$ until further laboratory processing.

\section{Statistical Analysis}

We performed an intention-to-treat analysis in which all calves were analyzed in the group to which they were initially assigned (Gupta, 2011). Means, proportions, and standard errors were calculated for baseline characteristics at enrollment. Potential baseline differences between treatment groups were tested using model-based approaches that accounted for nonindependence of calves within farms. A linear regression model (PROC GLM, SAS version 9.4, SAS Institute Inc., Cary, NC) was used to test for differences in continuous variables (temperature, packed cell volume, and total serum protein) at enrollment. A logistic regression model (PROC GLIMMIX, SAS version 9.4) was used to test for differences in age and dichotomized fecal, dehydration, and depression scores between treatment groups at enrollment.

A Poisson regression model (PROC GENMOD, SAS version 9.4) with robust standard errors (Zou, 2004) was used to identify differences in the rate (across 6 observation days) of diagnosed diarrhea, depression, dehydration, and signs of respiratory disease (cough or ocular discharge and ear droop) post-diarrhea treatment. Very few cases of complicated diarrhea or signs of nasal discharge were diagnosed posttreatment; thus, these variables were excluded from further analyses. The experimental unit and the unit of observation were the calf, and the outcome for the model was the count of observed days with disease divided by a total of 6 calf-days at risk. Because health assessments were performed on 6 occasions post-diarrhea treatment (d 3, 7, 14, 21, 28, and 35), each calf contributed a maximum of 6 calf-days. Due to study limitations, fewer calves had d 3 (control: $\mathrm{n}=149$; lactoferrin: $\mathrm{n}=168$ calves with completed observations) and d 35 (control: $\mathrm{n}=$ 168; lactoferrin: $\mathrm{n}=169$ calves with completed observations) follow-up health assessments. Baseline (day of enrollment) health assessment variables, including packed cell volume, total serum protein, age, dehydration, depression, and signs of respiratory disease, were retained in the model if the univariable $P$-value was $<0.20$ or if inclusion of the variable changed the treatment effect (risk ratio) measure by $>20 \%$. Despite robust randomization procedures, calf age at enrollment differed between treatment groups and farm and was thus included in the model to account for variation in age at enrollment. The final model included treatment, farm, and calf age at enrollment. Rate ratios for diarrhea, depression, dehydration, and signs of respiratory disease and the associated 95\% confidence intervals were derived from the model using the "estimate" statement.

Disease treatments and mortality and culling are described descriptively across the lactoferrin and control treatment groups, and the sum of producer-recorded treatments and deaths and culls was used for the statistical analysis. A Poisson regression model was used to test differences in the incidence risk of treatment and 
Table 3. Characteristics of calves with diarrhea at enrollment for the control $(\mathrm{n}=242)$ and lactoferrin $(\mathrm{n}=$ 243) treatment groups

\begin{tabular}{|c|c|c|c|c|}
\hline \multirow[b]{2}{*}{ Variable } & \multicolumn{2}{|c|}{ Treatment } & \multirow[b]{2}{*}{$\mathrm{SE}$} & \multirow[b]{2}{*}{$P$-value } \\
\hline & Control & Lactoferrin & & \\
\hline Median age (d) & 10.5 & 11.0 & - & 0.05 \\
\hline Packed cell volume (\%) & 32.8 & 32.7 & 0.41 & 0.85 \\
\hline Serum total protein $(\mathrm{g} / \mathrm{dL})$ & 6.2 & 6.2 & 0.04 & 0.50 \\
\hline Mean rectal temperature $\left({ }^{\circ} \mathrm{C}\right)$ & 39.1 & 39.1 & 0.06 & 0.44 \\
\hline Severe diarrhea $($ score $=3 ;$ no., $\%)$ & $123(50.8)$ & $128(52.7)$ & - & 0.78 \\
\hline Diarrhea + depression (no., $\%$ ) & $19(7.9)$ & $18(7.4)$ & - & 0.85 \\
\hline Diarrhea + fever (no., \%) & $49(20.5)$ & $45(18.8)$ & - & 0.66 \\
\hline Dehydration (skin tent $>3 \mathrm{~s}$; no., $\%$ ) & $47(19.4)$ & $43(17.7)$ & - & 0.66 \\
\hline Depression ( score $\geq 2 ;$ no., $\%$ ) & $19(7.9)$ & $18(7.4)$ & - & 0.85 \\
\hline
\end{tabular}

mortality and culling before $120 \mathrm{~d}$ following diarrhea diagnosis. The univariable $P$-value for severity of dehydration at enrollment was $<0.20$. Thus, the final model included treatment, farm, calf age at enrollment, and baseline dehydration status. Risk ratio estimates were derived from the model using the "estimate" statement. Significance and tendencies were declared at $P \leq 0.05$ and $P \leq 0.10$, respectively.

\section{RESULTS}

\section{Enrollment}

From March to August 2017, 492 calves were initially enrolled in the study; however, 1 bull calf was inadvertently enrolled, 1 calf received both lactoferrin and water (control) treatments at enrollment, and treat- ment group was not properly identified for 5 calves. In total, 242 and 243 calves were enrolled in the control and lactoferrin treatment groups, respectively. The median age of calves at enrollment was $11 \mathrm{~d}$ and ranged from 1 to $26 \mathrm{~d}$ (Figure 1). Four calves were $>21 \mathrm{~d}$ of age at enrollment but remained in the analysis to stay consistent with the intention-to-treat approach (Gupta, 2011). Baseline characteristics, except for calf age at enrollment, did not differ between treatment groups (Table 3).

Beyond experimental or concurrent farm therapies for diarrhea at study enrollment, $12.2 \%(59 / 243)$ and $11.8 \%(57 / 242)$ of calves in the lactoferrin and control treatment groups, respectively, received at least 1 farmadministered treatment for any disease in the $120 \mathrm{~d}$ following diarrhea diagnosis. For calves that received lactoferrin, the risk ratio of farm treatment was 1.09

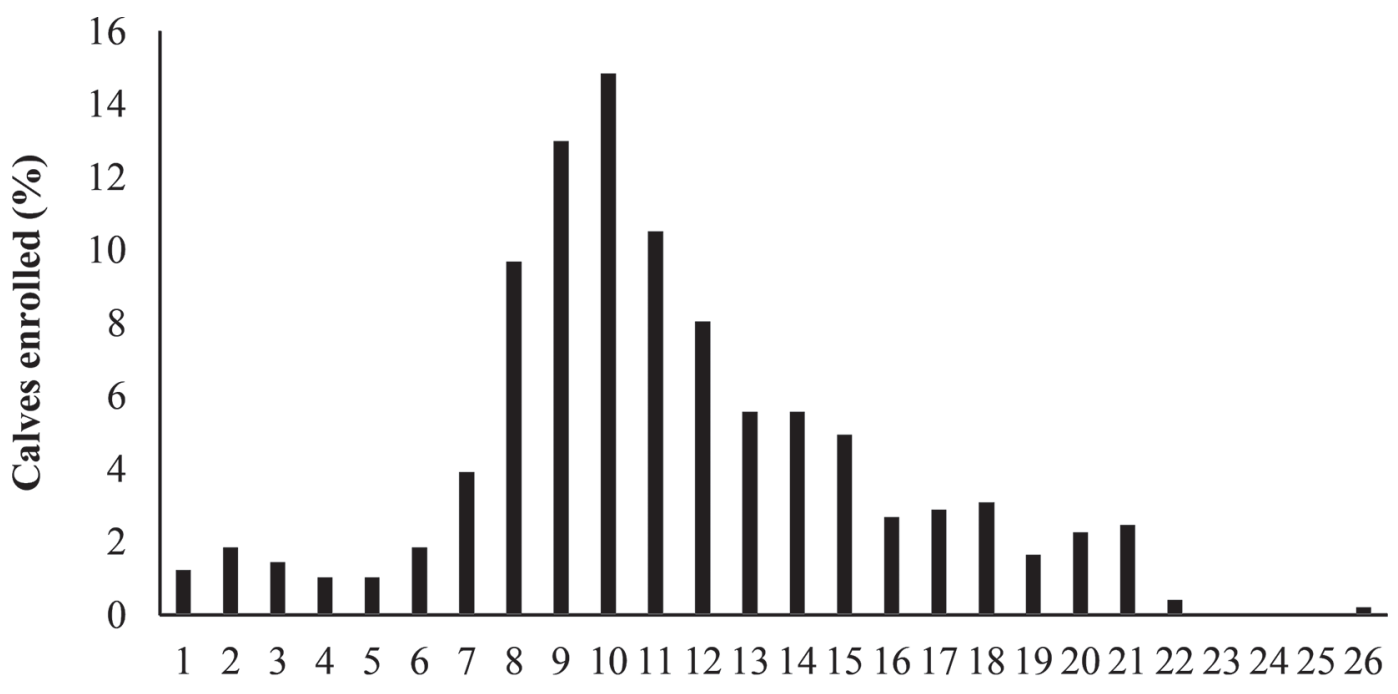

\section{Age of calves at enrollment (d)}

Figure 1. Age of dairy calves at first diarrhea diagnosis and enrollment in the study. 
(95\% CI: $0.76-1.58 ; P=0.63)$, and there was no significant interaction between farm therapy and lactoferrin effect.

\section{Diarrhea Incidence and Risk of Disease}

Twelve calves (control: $\mathrm{n}=9$ calves; lactoferrin: $\mathrm{n}=$ 3 calves) died or were removed from the herd before the final observation day at $35 \mathrm{~d}$ post-diarrhea diagnosis. However, these calves remained in the analysis, and the last measurement for each calf before study removal was retained to remain consistent with the last available observation carried forward method (Streiner and Geddes, 2001) and intention-to-treat analysis.

In total, $61.4 \%(143 / 233)$ and $65.4 \%(157 / 240)$ of calves in the control and lactoferrin treatment groups, respectively, had at least 1 observed incident of diarrhea post-experimental treatment (d 3-35), with $16.7 \%$ $(39 / 233)$ and $16.3 \%(39 / 240)$ of cases being severe $($ fecal score $=3)$. The proportion of calves with diarrhea differed by day, and $45.0 \%(67 / 149)$ and $51.8 \%$ $(87 / 168)$ of calves in the control and lactoferrin treatment groups, respectively, were clinically diagnosed with diarrhea following treatment completion on $\mathrm{d} 3$ (Figure 2). Lactoferrin supplementation tended to reduce the risk of diarrhea $14 \mathrm{~d}$ post-diarrhea diagnosis (Figure 3). Across the 6 observation days post-diarrhea treatment, the frequency of diagnosed diarrhea, depression, dehydration, or signs of respiratory disease did not differ between the control and lactoferrin treatment groups (Table 4).

\section{Risk Ratio for Death or Culling}

In total, $9.9 \%$ (48/485) of enrolled calves died or were culled from the herd in the $120 \mathrm{~d}$ following diarrhea diagnosis, with $10.7 \%(22 / 243)$ and $9.1 \%(26 / 242)$ in the lactoferrin and control groups, respectively. The number of reported deaths and culls varied significantly across farms $(P<0.001)$, ranging from 4.0 to $19.9 \%$ in the $120 \mathrm{~d}$ following enrollment. Age and cause of death were not consistently recorded across farms. The 120-d risk of death or culling was numerically lower but not significantly different for calves receiving lactoferrin for treatment of diarrhea compared with calves in the control group (risk ratio: $0.87 ; 95 \%$ CI: $0.49-1.54$ ), and there was no significant farm $\times$ treatment interaction. Of the calves that died or were culled from the herd, $50 \%(28 / 48)$ had severe diarrhea (fecal score $=3$ ) at study enrollment. For the subset of calves with a fecal score of 3 , the risk of death or culling was numerically but not significantly lower for calves treated with lactoferrin (relative risk: $0.75 ; 95 \% \mathrm{CI}: 0.35-1.59 ; P$-value $=0.45)$.

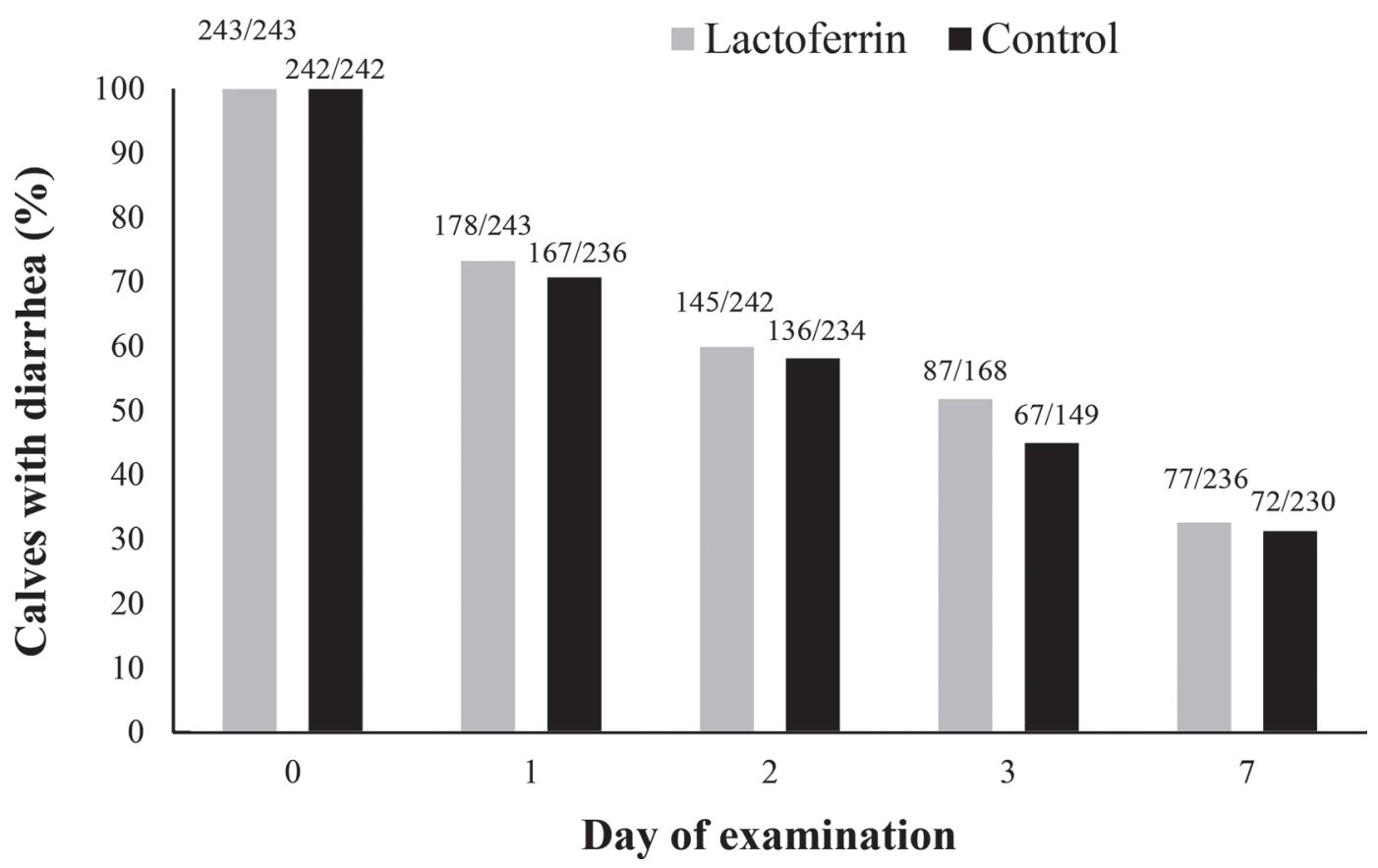

Figure 2. The proportion of preweaned dairy calves with diarrhea (fecal score $=2$ or 3 ) at first diarrhea diagnosis $(\mathrm{d} 0)$ and $1,2,3$, and 7 d postdiagnosis. Calves were treated with lactoferrin (gray bars) or water (control; black bars) on d 0, 1, and 2. 
Table 4. Effect of treatment with lactoferrin on the relative risk of diarrhea, dehydration, depression, and signs of respiratory disease post-diarrhea treatment in reference to the control group ${ }^{1}$

\begin{tabular}{lccc}
\hline Variable & Rate ratio & 95\% CI & $P$-value \\
\hline Diarrhea (score $\geq 2)$ & 1.04 & $0.87-1.23$ & 0.65 \\
Severe diarrhea (score $=3$ ) & 0.93 & $0.62-1.40$ & 0.74 \\
Dehydration (skin tent $>3$ s; score $\geq 2$ ) & 0.95 & $0.59-1.51$ & 0.81 \\
Depression $($ score $\geq 2)$ & 1.11 & $0.61-2.03$ & 0.74 \\
Cough $($ score $\geq 2$ ) & 1.10 & $0.78-1.55$ & 0.56 \\
Ocular discharge and ear droop (score $\geq 2)$ & 1.31 & $0.87-1.98$ & 0.19 \\
\hline
\end{tabular}

${ }^{1}$ Calves were clinically evaluated $3,7,21,28$, and $35 \mathrm{~d}$ following diarrhea diagnosis.

\section{DISCUSSION}

Randomized clinical trials are necessary to determine the effectiveness of alternative therapies for calf diarrhea to reduce overall antimicrobial use on dairy farms. This is the first multisite, randomized clinical trial to evaluate the effectiveness of lactoferrin as a treatment for diarrhea in preweaned dairy calves. A strength of this research study includes the enrollment of multiple dairy farms, increasing the generalizability of the findings. Inclusion of multiple farms also reduces the risk of potential selection bias and confounding variables that may be associated with one farm. Additional strengths of this study include robust randomization and blinding procedures. One potential pitfall of this study, and a common limitation of randomized clinical trials, is missing data from a subset of calves during follow-up evaluations. To limit potential biases associated with exclusions, we used an intention-to-treat analysis, one of the most clinically informative and statistically robust methods of analysis for randomized clinical trials with missing data (Streiner and Geddes, 2001).
In this study, supplementing calves with lactoferrin at first diarrhea diagnosis did not reduce calves' risk of disease within $35 \mathrm{~d}$ following diagnosis. Similarly, the risk of producer-diagnosed disease treatment 120 d following diarrhea diagnosis was similar between the lactoferrin and control treatment groups. Previous studies have reported that lactoferrin improved fecal consistency in calves when supplemented $1 \mathrm{~g} / \mathrm{d}$ from $3 \mathrm{~d}$ of age to 2 wk postweaning (Robblee et al., 2003). Prenner et al. (2007) also reported fewer diseased days and reduced severity of diarrhea cases in calves supplemented with lactoferrin at $0.16 \%$ from birth to $70 \mathrm{~d}$ of age. Lactoferrin supplementation, however, in our current and previous studies was used as a treatment for naturally occurring cases of calf diarrhea as opposed to blanket supplementation for disease prevention. Additional studies with varying doses are necessary to assess the longer-term effects of lactoferrin as a treatment for calf diarrhea.

Lactoferrin treatment tended to reduce the risk of diarrhea $14 \mathrm{~d}$ following diagnosis. This result was unexpected. It is possible that lactoferrin may have a pro-

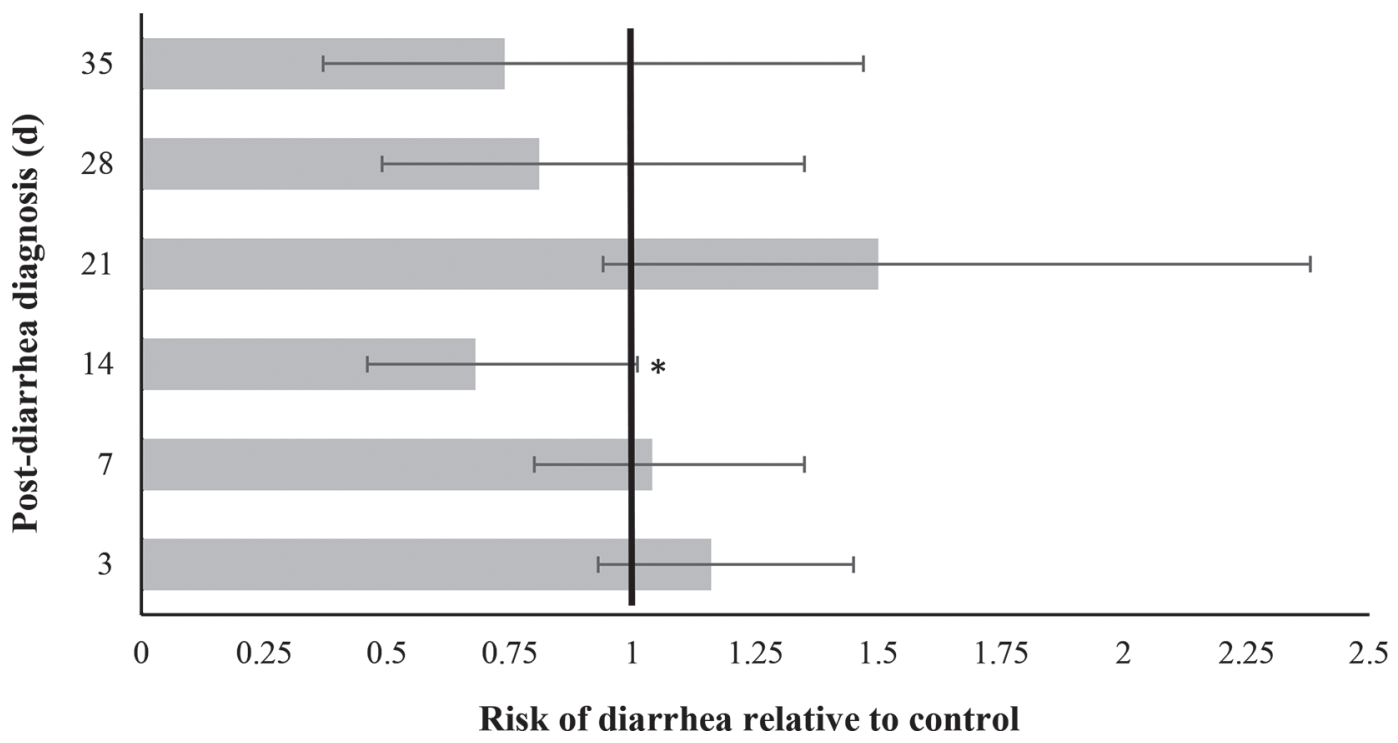

Figure 3. Relative risk $(95 \% \mathrm{CI})$ of diarrhea (fecal score $=2$ or 3 ) following a 3 -d dose of lactoferrin or water $($ control). $* P=0.09$. 
tective effect against certain pathogens, such as bovine rotavirus or coronavirus, which usually causes diarrhea in calves 1 to 2 wk of age (Cho and Yoon, 2014). Although we accounted for as many variables as possible that may have influenced our outcomes, it is also quite possible that this is merely a spurious relationship.

Furthermore, we observed no difference between treatments in the frequency of clinical signs associated with respiratory disease, such as ocular discharge or ear droop or cough. We hypothesized that the observed reduction in mortality and culling for calves treated with lactoferrin in our former trial may have been due to reduced severity or frequency of respiratory disease, yet the results of our current study do not support this idea. To our knowledge, very little research has been conducted to determine the influence of lactoferrin on respiratory disease in young dairy calves. However, a recent study reported a reduction in the incidence rate of respiratory- and diarrheal-related illnesses in human infants supplemented with lactoferrin-fortified formula for 3 mo (Chen et al., 2016). Additionally, a pilot study by King et al. (2007) reported significantly fewer lower respiratory tract infections in infants when supplemented with lactoferrin for $12 \mathrm{mo}$; however, further studies are needed to corroborate these results. Thus, it is possible that lactoferrin may have beneficial effects on calf morbidity if supplemented throughout and beyond the preweaning period, but in contrast to our prior findings, the results of this study suggest little to no long-term effect on health when used as a 3 -d treatment for early cases of calf diarrhea.

In our former trial, lactoferrin significantly reduced the 60- and 120-d risk of mortality and culling when used as a treatment for diarrhea (Habing et al., 2017). That trial, however, was conducted on an organic operation, and differences in mortality and culling were observed in lieu of antimicrobial therapies (Habing et al., 2017). In the current study, experimental treatments (lactoferrin and control) were administered as an adjunct to antimicrobial therapies, per farm treatment protocols. In other words, the farms enrolled in this study did not alter their disease treatment protocols, and farms continued to treat cases of diarrhea and other diseases independent of research staff diagnosis. Thus, it is possible that the antimicrobial therapies administered by farm personnel masked the potential beneficial effect of lactoferrin on calf morbidity and mortality. It is also possible that we did not have the statistical power to detect a significant difference with the mortality estimates used for the power analysis calculations, as the case-mortality rate was lower than expected. Future clinical trials on multiple organic dairy operations and on conventional operations with more calves should be considered.

\section{CONCLUSIONS}

The results of this study suggest that a 3 -d oral dose of lactoferrin at first diarrhea diagnosis does not reduce the risk of future morbidity or mortality in dairy calves. Additional research on multiple organic dairy operations should be conducted to evaluate whether lactoferrin would be most useful as a treatment for diarrhea in organic herds. Further analyses or challenge models are also necessary to identify the cause of discrepant results of the current and prior trials of lactoferrin.

\section{ACKNOWLEDGMENTS}

The authors are grateful for the support of the farms involved with this study and for their cooperation and use of their animals and facilities. The authors also thank Abby Bonnot, Kadey Starkey (both of Ohio Agricultural Research and Development Center, The Ohio State University, Wooster), and Karishma Nayak (The Ohio State University College of Veterinary Medicine, Columbus) for their assistance with data collection.

\section{REFERENCES}

Chen, K., L. Chai, H. Li, Y. Zhang, H. M. Xie, J. Shang, W. Tian, P. Yang, and A. C. Jiang. 2016. Effect of bovine lactoferrin from iron-fortified formulas on diarrhea and respiratory tract infections of weaned infants in a randomized controlled trial. Nutrition $32: 222-227$.

Cho, Y. I., and K. J. Yoon. 2014. An overview of calf diarrhea-Infectious etiology, diagnosis, and intervention. J. Vet. Sci. 15:1-17.

Conneely, O. M. 2001. Anti-inflammatory activities of lactoferrin. J. Am. Coll. Nutr. 20(E-Suppl. 5):389-395.

Constable, P. D. 2004. Antimicrobial use in the treatment of calf diarrhea. J. Vet. Intern. Med. 18:8-17.

Constable, P. D., P. G. Walker, D. E. Morin, and J. H. Foreman. 1998. Clinical and laboratory assessment of hydration status of neonatal calves with diarrhea. J. Am. Vet. Med. Assoc. 212:991-996.

Embleton, N. D., J. E. Berrington, W. McGuire, C. J. Stewart, and S. P. Cummings. 2013. Lactoferrin: Antimicrobial activity and therapeutic potential. Semin. Fetal Neonatal Med. 18:143-149.

Gupta, S. K. 2011. Intention-to-treat concept: A review. Perspect. Clin. Res. 2:109-112.

Habing, G., K. Harris, G. M. Schuenemann, J. M. Piñeiro, J. Lakritz, and X. Alcaraz Clavijo. 2017. Lactoferrin reduces mortality in preweaned calves with diarrhea. J. Dairy Sci. 100:3940-3948.

Joslin, R. S., P. S. Erickson, H. M. Santoro, N. L. Whitehouse, C. G. Schwab, and J. J. Rejman. 2002. Lactoferrin supplementation to dairy calves. J. Dairy Sci. 85:1237-1242.

Kahn, C. M., S. Line, and S. E. Aiello. 2010. The Merck Veterinary Manual. 10th ed. Merck, Whitehouse Station, NJ.

King, J. C. Jr., G. E. Cummings, N. Guo, L. Trivedi, B. X. Readmond, V. Keane, S. Feigelman, and R. de Waard. 2007. A double-blind, placebo-controlled, pilot study of bovine lactoferrin supplementation in bottle-fed infants. J. Pediatr. Gastroenterol. Nutr. 44:245251.

Manzoni, P. 2016. Clinical benefits of lactoferrin for infants and children. J. Pediatr. 173:S43-S52.

Manzoni, P., I. Stolfi, H. Messner, S. Cattani, N. Laforgia, M. G. Romeo, L. Bollani, M. Rinaldi, E. Gallo, M. Quercia, M. Maule, M. Mostert, L. Decembrino, R. Magaldi, F. Mosca, F. Vagnarelli, L. Memo, P. M. Betta, M. Stronati, and D. Farina. 2012. Bovine lac- 
toferrin prevents invasive fungal infections in very low birth weight infants: A randomized controlled trial. Pediatrics 129:116-123.

McGuirk, S. M. 2008. Disease management of dairy calves and heifers. Vet. Clin. North Am. Food Anim. Pract. 24:139-153.

Ochoa, T. J., E. Chea-Woo, N. Baiocchi, I. Pecho, M. Campos, A. Prada, G. Valdiviezo, A. Lluque, D. Lai, and T. G. Cleary. 2013. Randomized double-blind controlled trial of bovine lactoferrin for prevention of diarrhea in children. J. Pediatr. 162:349-356.

Pammi, M., and S. A. Abrams. 2015. Oral lactoferrin for the prevention of sepsis and necrotizing enterocolitis in preterm infants. Cochrane Database Syst. Rev. 2:CD007137.

Pereira, R. V., J. D. Siler, J. C. Ng, M. A. Davis, Y. T. Grohn, and L. D. Warnick. 2014. Effect of on-farm use of antimicrobial drugs on resistance in fecal Escherichia coli of preweaned dairy calves. J. Dairy Sci. 97:7644-7654.

Prenner, M. L., C. Prgomet, H. Sauerwein, M. W. Pfaffl, J. Broz, and F. J. Schwarz. 2007. Effects of lactoferrin feeding on growth, feed intake and health of calves. Arch. Anim. Nutr. 61:20-30.
Puddu, P., P. Valenti, and S. Gessani. 2009. Immunomodulatory effects of lactoferrin on antigen presenting cells. Biochimie 91:11-18.

Robblee, E. D., P. S. Erickson, N. L. Whitehouse, A. M. McLaughlin, C. G. Schwab, J. J. Rejman, and R. E. Rompala. 2003. Supplemental lactoferrin improves health and growth of Holstein calves during the preweaning phase. J. Dairy Sci. 86:1458-1464.

Streiner, D., and J. Geddes. 2001. Intention to treat analysis in clinical trials when there are missing data. Evid. Based Ment. Health 4:70-71.

USDA. 2018. Dairy 2014: Health and Management Practices on U.S. Dairy Operations, 2014. USDA, Fort Collins, CO.

World Health Organization. 2017. World Health Organization critically important antimicrobials for human medicine. 5th rev. Accessed May 10, 2018. http://who.int/foodsafety/publications/ antimicrobials-fifth/en/.

Zou, G. 2004. A modified Poisson regression approach to prospective studies with binary data. Am. J. Epidemiol. 159:702-706. 